\title{
Buckling Strengths of Composite Plate Using Shape Memory Alloy under In-Plane Shear
}

\author{
Yatendra Saraswat ${ }^{1}$, Hemant Singh Parihar $^{2}$ \\ ${ }^{1}$ Assistant professor Department of Civil Engineering GLA University, Mathura, UP, India. \\ ${ }^{2}$ Assistant professor Department of Civil Engineering, GLA University, Mathura, UP, India. \\ yatendrasaraswat52@gmail.com ${ }^{1}$, hemantsingh.parihar@gla.ac.in ${ }^{2}$
}

Article History: Received: 10 November 2020; Revised: 12 January 2021; Accepted: 27 January 2021; Published online: 05 April 2021

\begin{abstract}
In this article, we analyze the strength and buckling response in the plane shear load fixed at the corner of the composite plate. The fem is formulated is done on the basis of first-order shear deformation theory and assumptions of von Karman. The Newton-Raphson technique is considered to analyze the non-linearity algebraic equation. The effect of shape memory alloy in shear load and buckling response is discussed. In this study we analyze the two cases in the first simple carbon/epoxy plate is analyze and then we use the shape memory wire embedded in the plate which is about $1 \%$ of the volume of the plate and studies the buckling response effect on the plate. In the second case we use Shape Memory Alloy plate and loading but a circular cutout at the middle of the plate this case we analyze for both with the use of shape memory alloy and without the use of shape memory. It is observed that the shape memory alloy increases the strength of the plate in both cases. The whole simulations are done using Ansys workbench software v 2020R2.
\end{abstract}

Keywords: Shape Memory Alloy; Finite Element Method; Newton-Raphson method; ANSYS work bench; carbon epoxy plate; first-ordershear deformation theory

\section{Introduction}

In the last few years, the need for advanced structures promoted the evolution of Shape Memory Alloy materials [1].

From those Shape Memory Alloy materials, shape memory alloys have their own identity. If we discuss the shape memory alloy then there are two main features of shape memory alloy i.e. super elasticity and regain its shape after deformation. The shape memory alloy could be used for control the shape of structural components for large non-linear strain, undesirable vibrations, impact resistance, etc. in present time our industries uses that components which are light in weight and has better strength. in the past decade most of the research work on different Shape Memory Alloy materials which come under these categories, known as Shape Memory Alloy material [2] [3]. Shape memory alloys are one of them. L.C Brinson (1993) developed a constitutive law for analyzed the effect of shape memory alloy thermodynamically [4]. In this work, authors simulating different cases for the stress-strain characteristic of shape memory bar in uniaxial loading as well as restrain recovery response for different temperature. S.M.R Khalil (2013) studied the dynamic analysis of a Shape Memory Alloy hybrid beam at impulse loading and show the material non-linear effect with the change in temperature [5][6]. A. Shokhufar (2008) developed a model of for show a low-velocity effect on the hybrid composite plate [9] [7] using the response surface method to show the effect of velocity impact on the surface of the plate and how the plate resists the low velocity [8] [13].M.M. Ghomshei (2005) study the finite element model for dynamic response of thick shape memory alloy composite beam [14]. He used a dimensional sinusoidal model for analyses of the beam. He also used the different fiber to check the maximum strength of the beam [11] [12] [13]. A. Niknami (2016) [10] study the low-velocity effect with shape memory alloy wire and show the effect of temperature on impact. Dinesh Kumar and S.B. Singh (2010) [15] study the buckling and post-buckling response of plate with the different cutout in the plate.

\section{Modeling and Simulation}

For modeling and examination of laminated beam with shape memory alloy and carbon-epoxy, ANSYS Workbench 15.0 version is to be used that depends on the Finite Element Method (FEM). ANSYS 15.0 has new features for composites, bolted connections, and improved mesh tools. The ANSYS Workbench platform provides a comprehensive and integrated system. ANSYS workbench provides higher productivity in product development simulation because it has an in-built application and access to Multi physics and system-level applications. In a simple carbon/epoxy plate there are about 98 nodes and 36 elements were used and in carbon epoxy with shape memory alloy embedded there are 26352 nodes and 31030 elements were used and for cutout cases, about 136 nodes and 55 elements with shape memory alloy wire used and with shape memory alloy 22416 nodes and 63749 elements were used to analyze. For the simulation work, first-order shear deformation theory and Newton-Raphson technique are used to analyze the non-linearity algebraic equation. Figure 1 shows the schematic of static analysis with buckling for all cases 


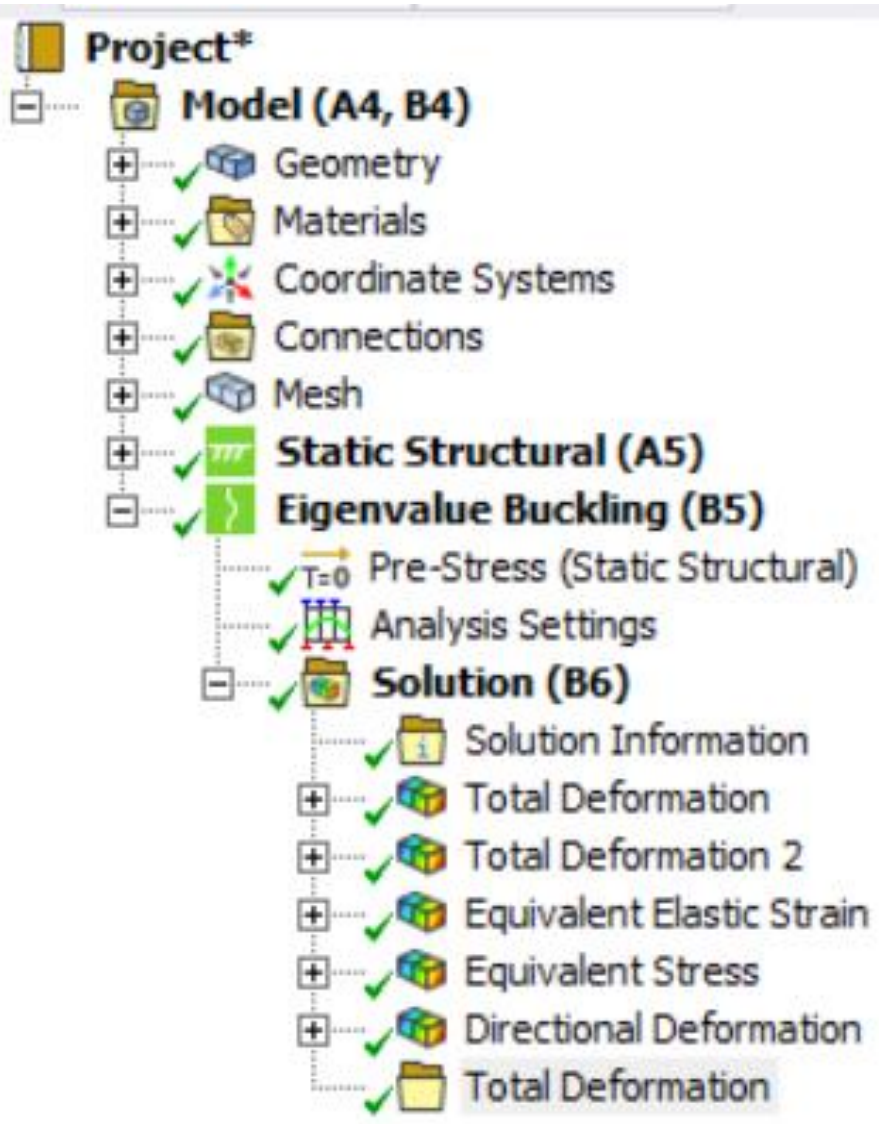

Figure1. Schematic of static analysis with buckling for all cases.

\section{Geometry}

SHAPE MEMORY ALLOY SMAs [16] belong to a class of metallic alloys, which can be restored to their actual form (shape or size) once it undergoes to a memorisation process between two transformation stages, which is either temperature or magnetic field based. This transformation principle is called as the shape memory effect (SME). The use of SMA can be classified into various types depending on the application domain, like automotive, aerospace, robotics and biomedical and also in other fields [17]. Shape memory alloys have significant characteristics including, One-way shape memory effect (OWSME): The one-way SMA (OWSMA) gets a malformed state once the external force is recoverd, and then restores its actual shape when heated. Twoway shape memory effect (TWSME) or reversible SME: Along with the one-way effect, a two-way SMA (TWSMA) can keep its shape in memory at both high and low temperatures. One more significant property is pseudoelasticity, and here on heating a SMA, it starts to change from martensite into the austenite stage. The [16] austenite-start-temperature (As) refers to the temperature where this change begins and the austenite-finishtemperature (Af) stands for the temperature where this change is completed. When a SMA is heated more it starts contracting and changes into the austenite structure i.e. to get back into its actual form. This change is feasible even when high loads are applied, and hence, high actuation energy densities are observed.

In this study first, a carbon/epoxy plate is the model. The shape memory alloy is embedded in the plate. In one more case simple carbon/epoxy plate with and without Shape Memory Alloy is model with a cutout at center of radius $5 \mathrm{~mm}$ is at the center of the plate as illustrated in the below Figure 2. Figure 3 shows the geometry of the plate with and with no shape memory alloy in the circular cut-out. 


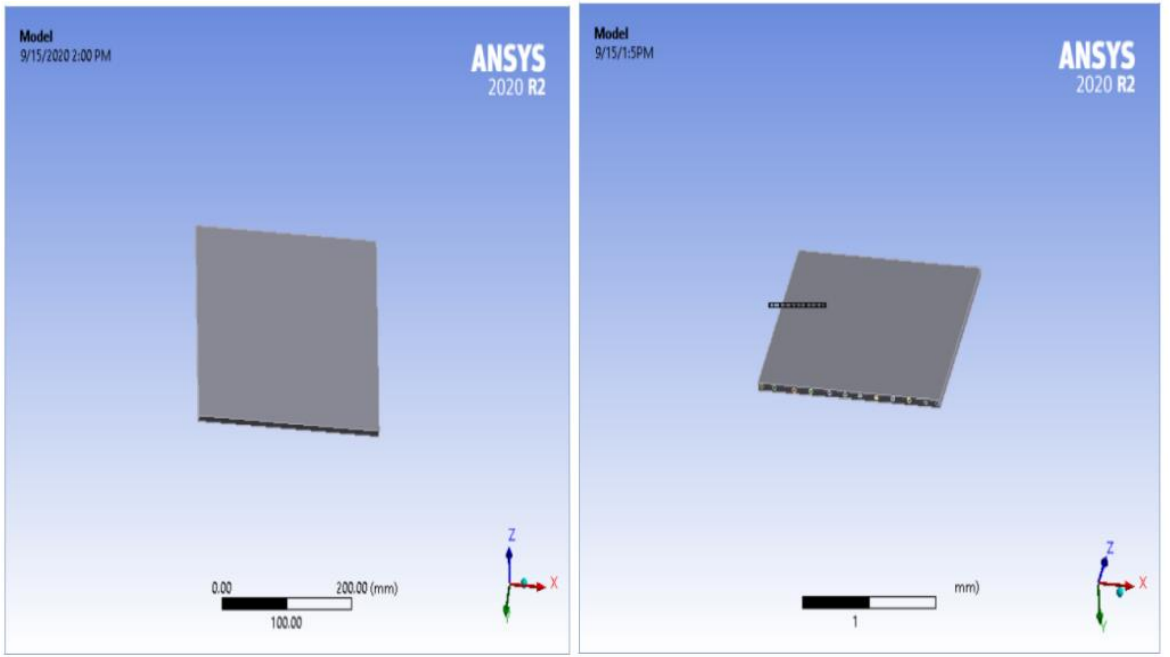

Figure2. The geometry of plate with and without shape memory alloy

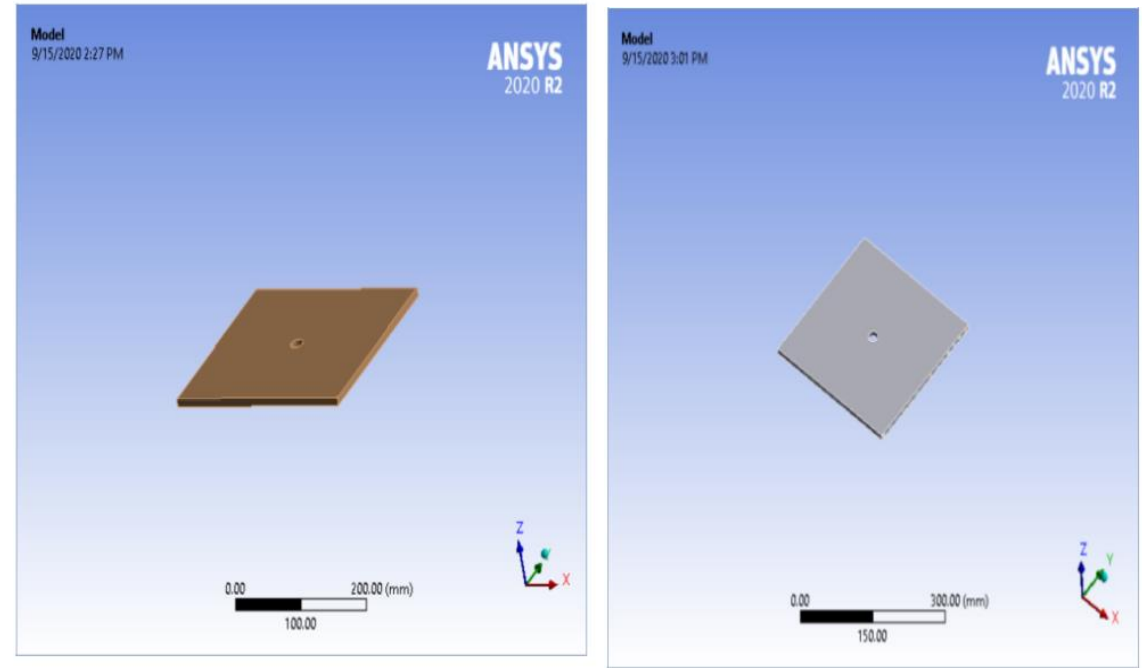

Figure 3. The geometry of the plate with and with no shape memory alloy in the circular cut-out.

\section{Loading and Boundary Conditions}

In this analysis, we fixed the corner and apply the force of $10 \mathrm{Kn}$ in positive plane shear as shown in the below figure 4 .
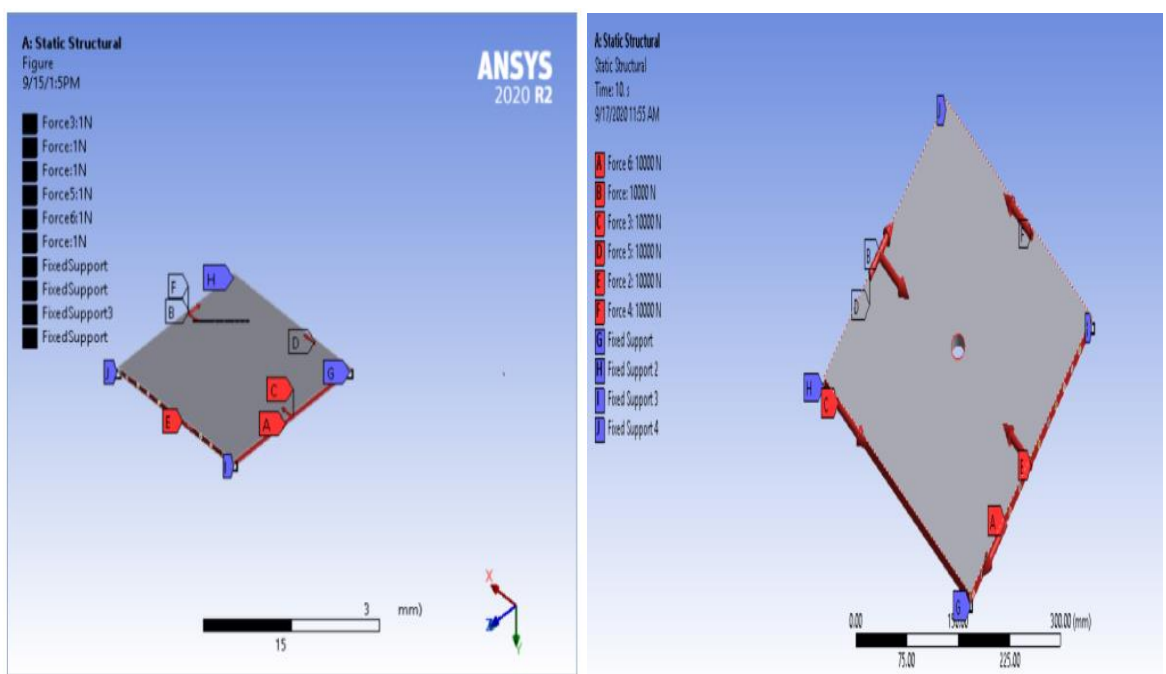

Figure 4. Show the force and support in both with and without cutout. 


\section{Results}

\subsection{Static Analysis}

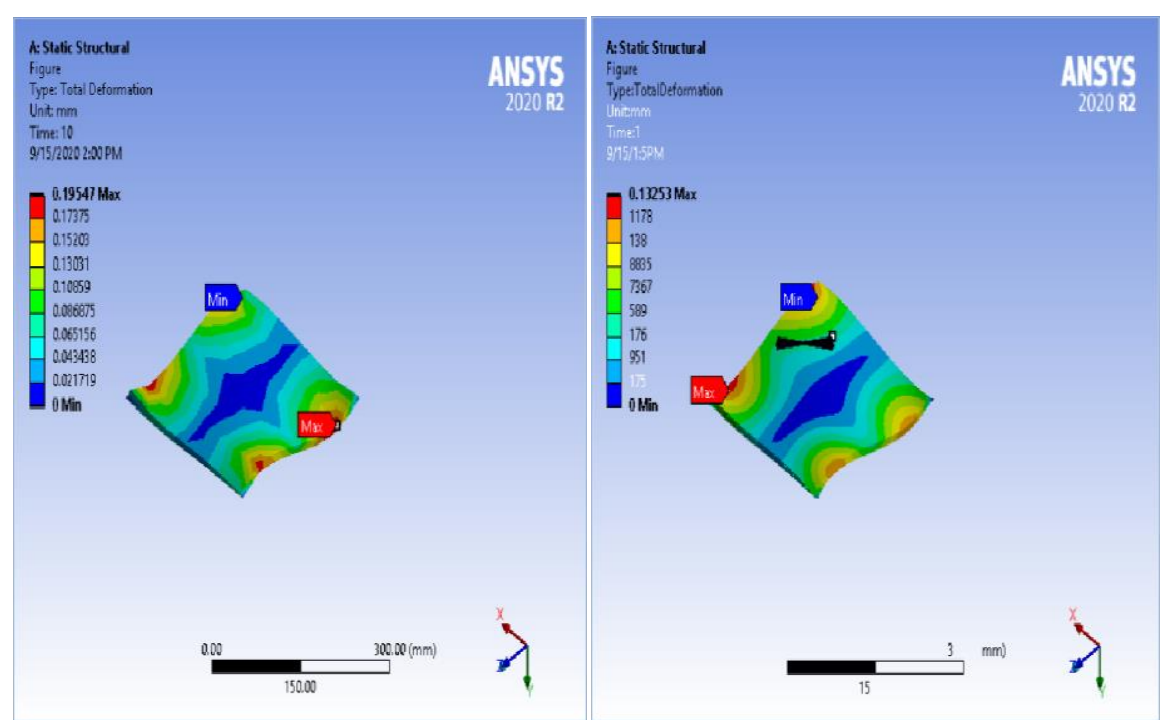

Figure 5. Total deformation with and with no Shape Memory Alloy.

Figure 5 shows the total deformation with and with no Shape Memory Alloy.

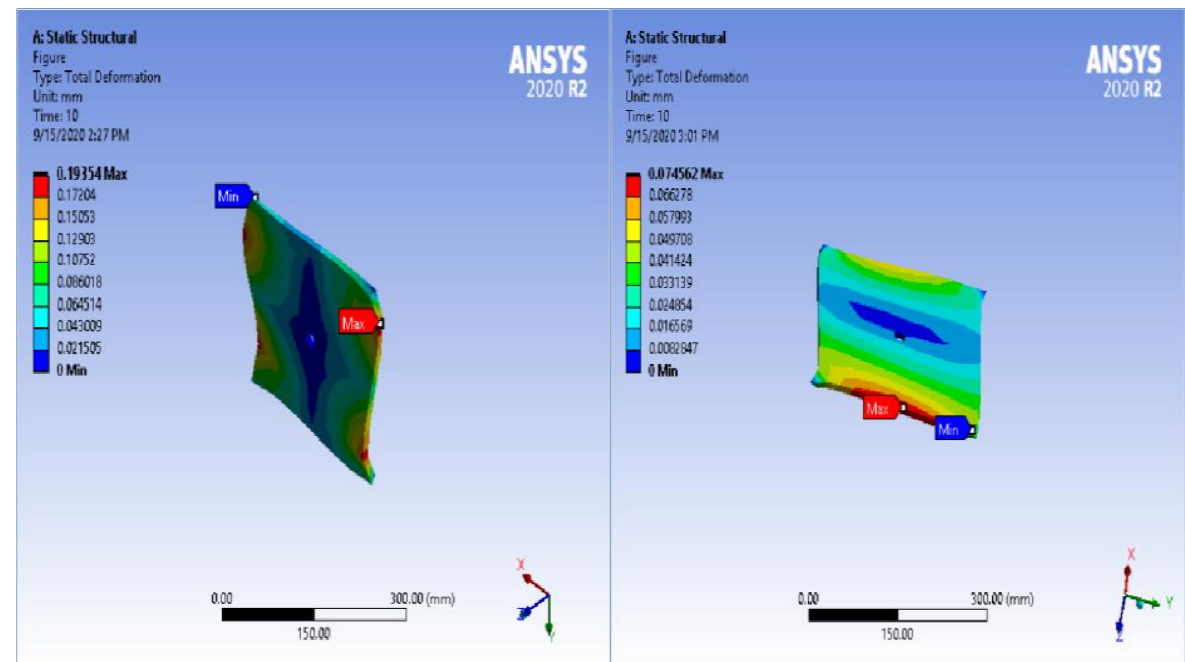

Figure 6. Total deformation with and without Shape Memory Alloy in cutout plate

Figure 6 shows the Total deformation with and without Shape Memory Alloy in cutout plate
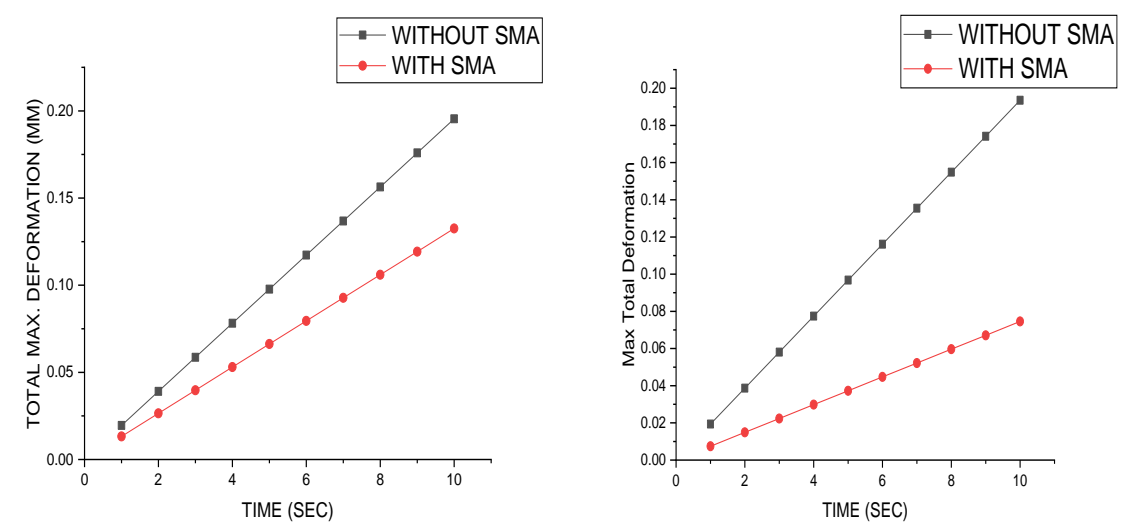
Graph 1. Total deformation in carbon epoxy plate with and without cutout.

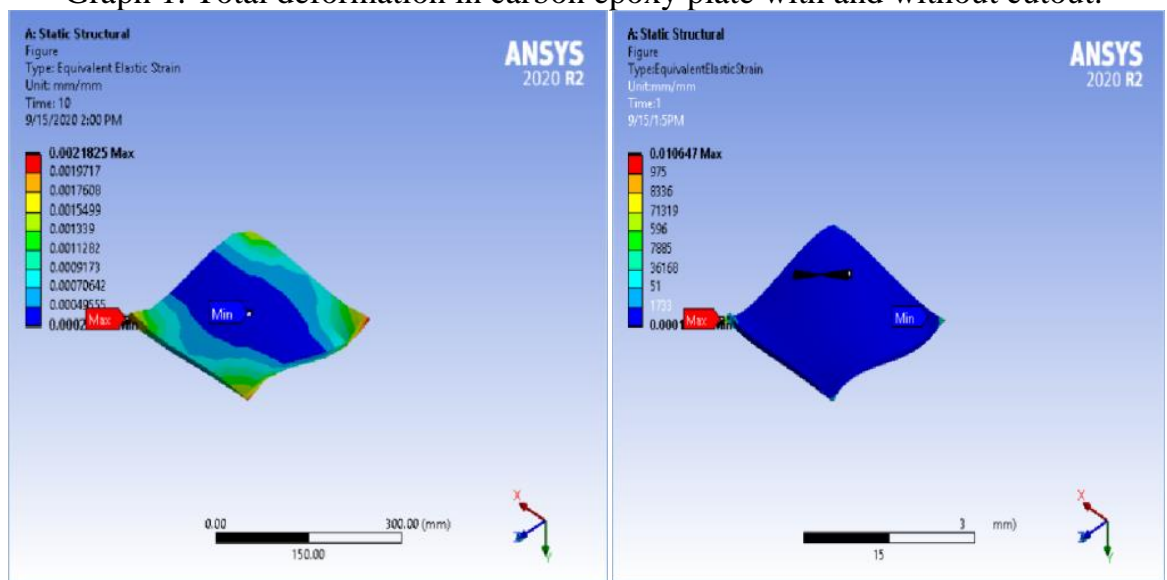

Figure 7. Equivalent elastic strain with and without shape memory alloy

Figure 7 shows the Equivalent elastic strain with and without shape memory alloy
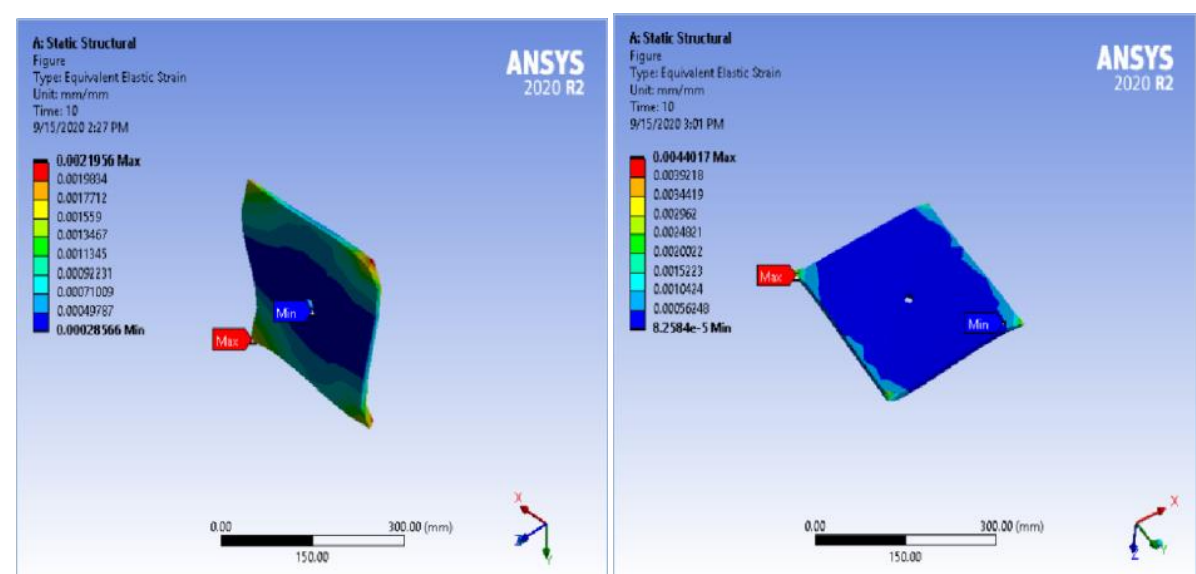

Figure 8. Equivalent elastic strain with and without shape memory alloy in cutout plate

Figure 8 shows the Equivalent elastic strain with and without shape memory alloy in cutout plate
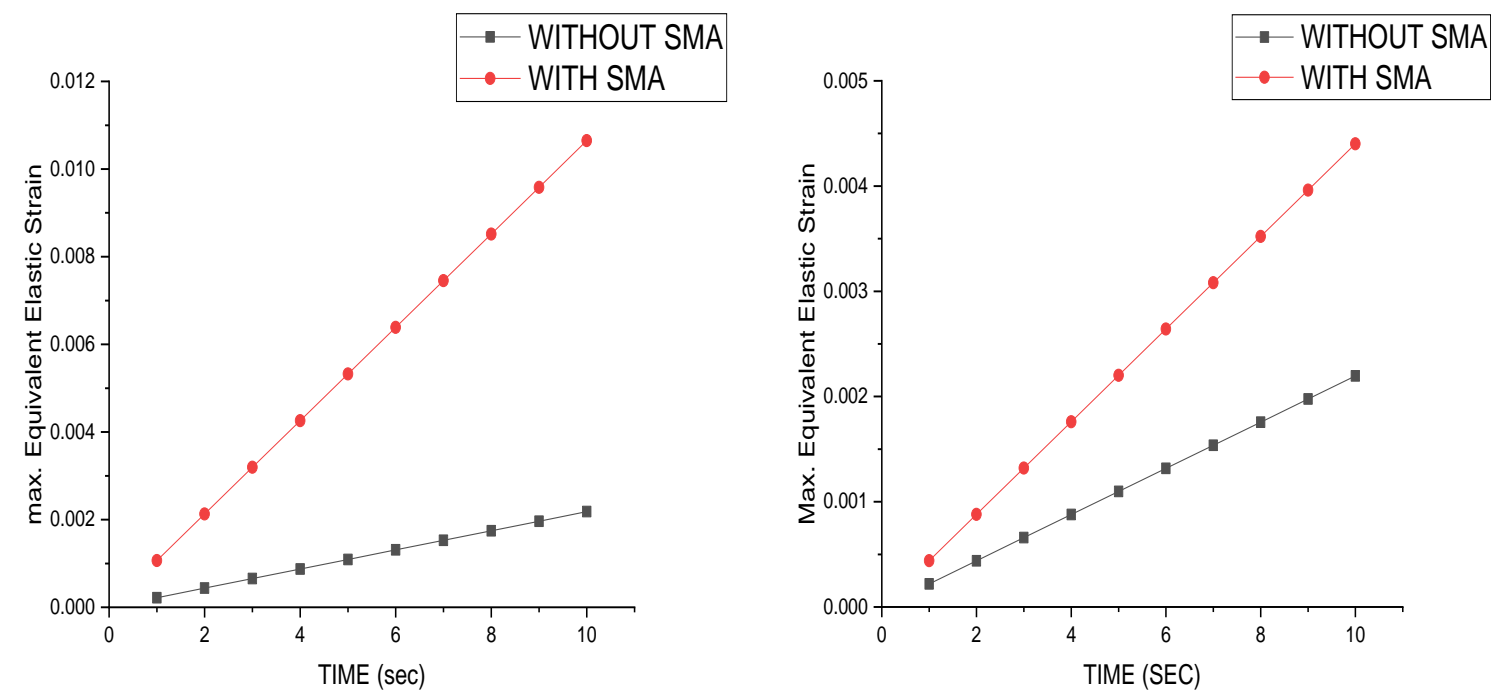

Graph 2. Max Equivalent strain with and without cutout. 


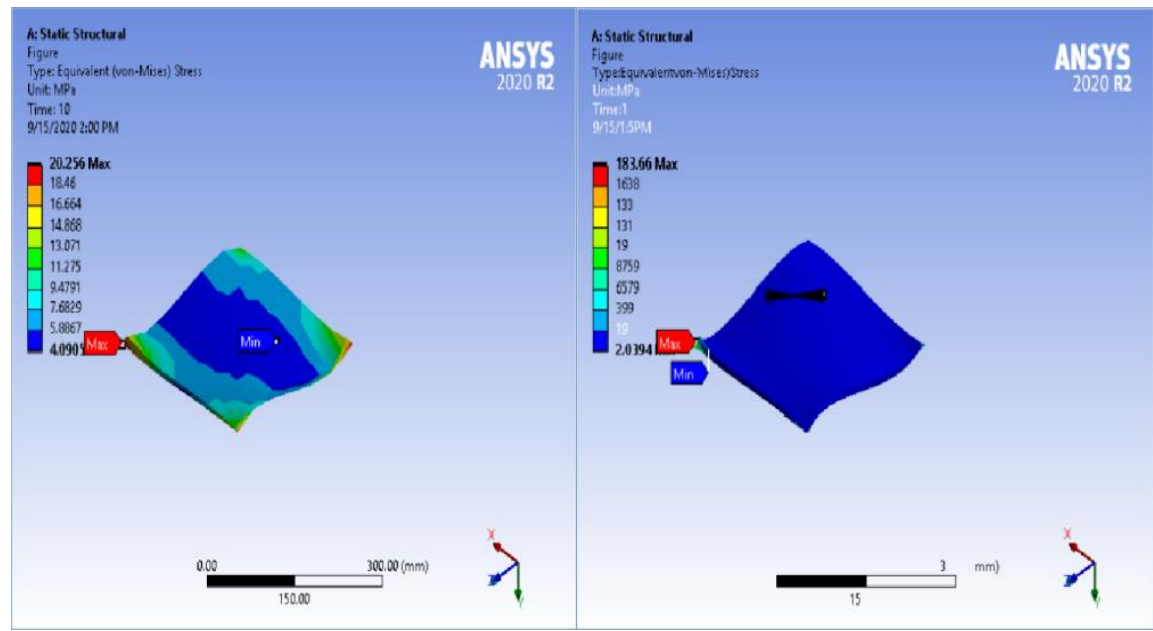

Figure 9. Equivalent stress with and without sma in carbon/epoxy plate.

Figure 9 shows the Equivalent stress with and without sma in carbon/epoxy plate

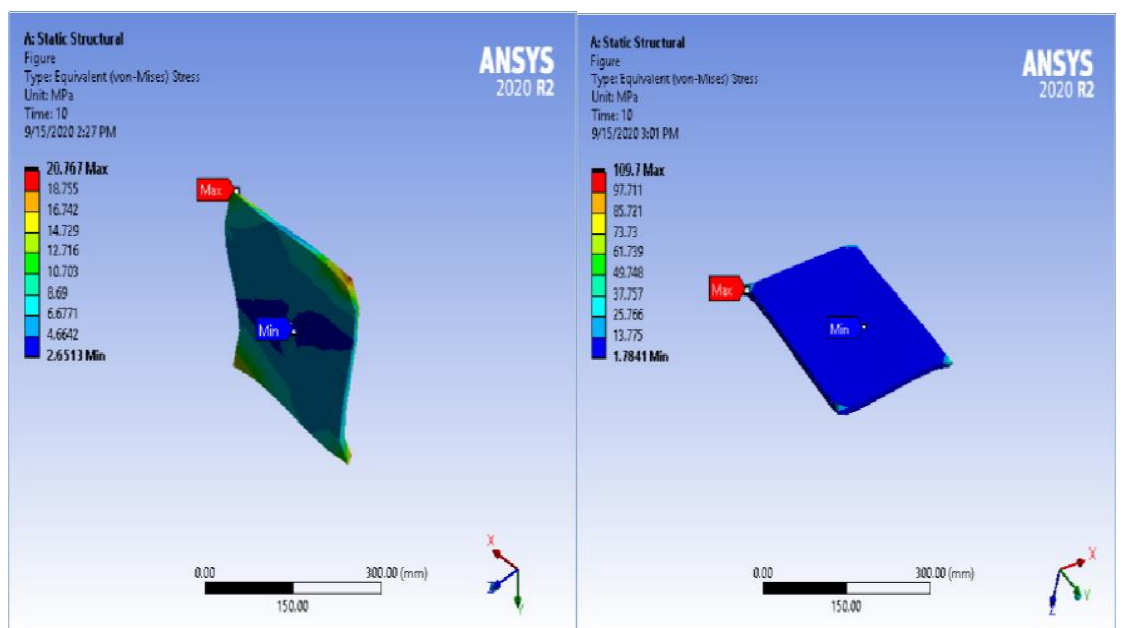

Figure 10. Equivalent stress with and without sma in carbon/epoxy plate with cutout.

Figure.10 shows the Equivalent stress with and without sma in carbon/epoxy plate with cutout
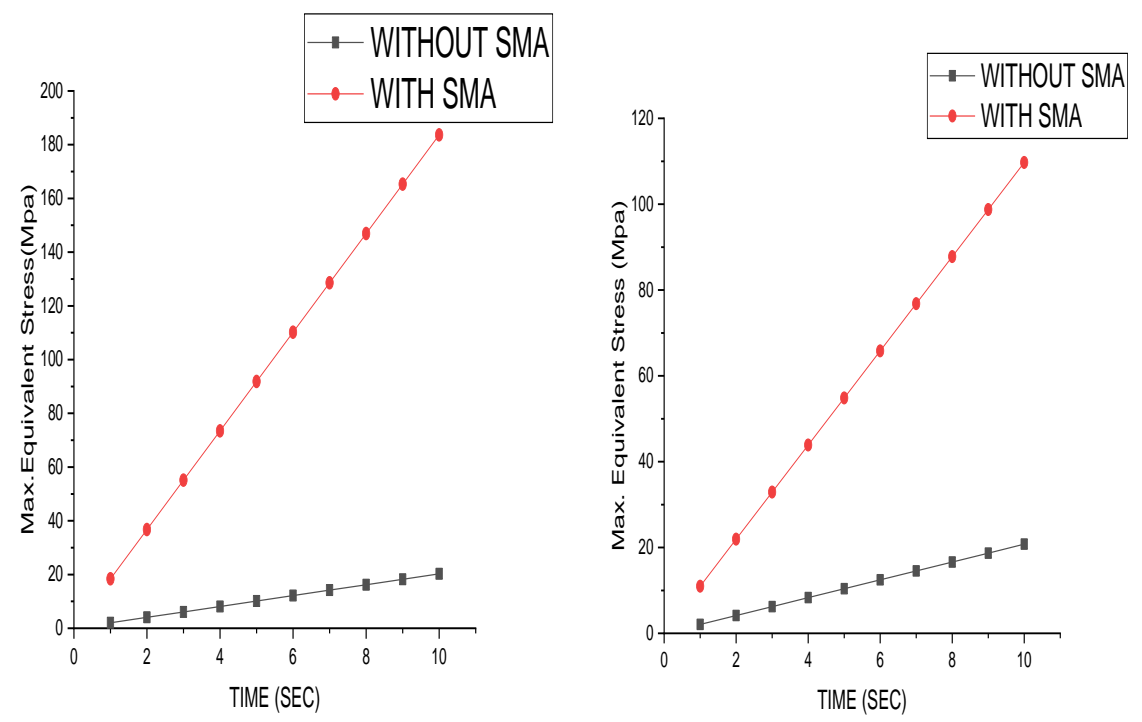

Graph 3. Max stress in with and without cutout plate. 


\subsection{Buckling Analysis}

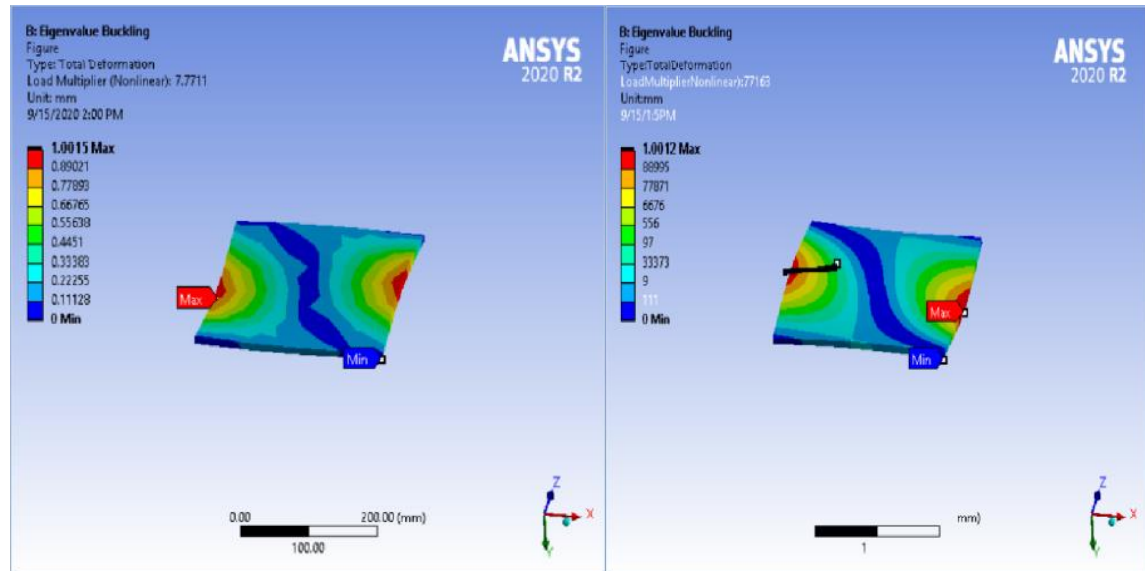

Figure 11. Total deformation after buckling in the carbon epoxy plate.

Figure11 shows the Total deformation after buckling in the carbon epoxy plate

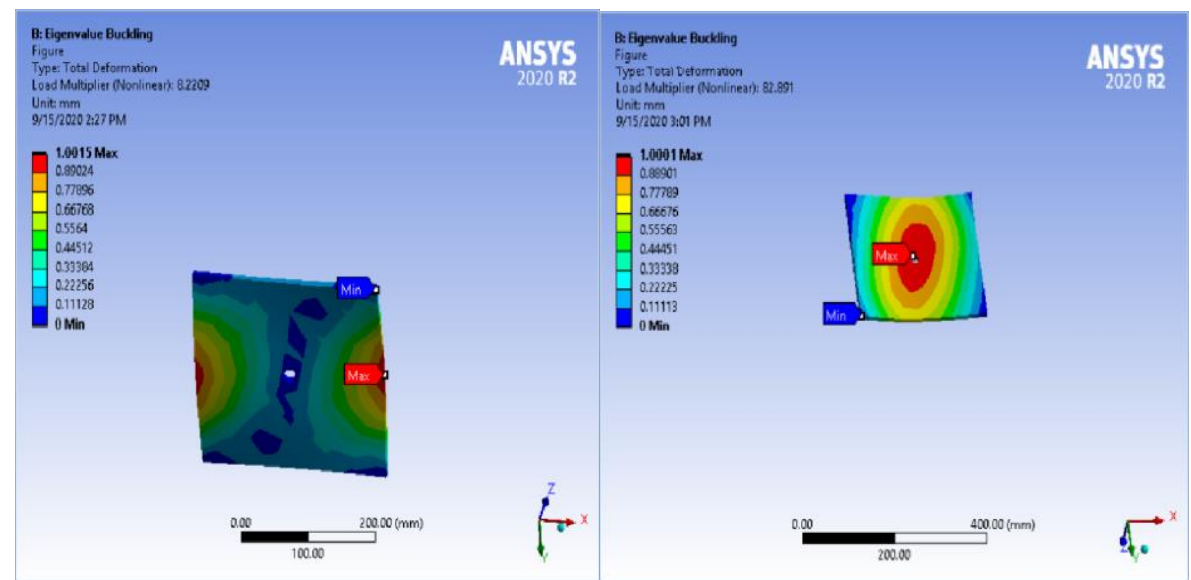

Figure 12. Total deformation after buckling in carbon epoxy plate with cutout

Figure 12 shows the Total deformation after buckling in carbon epoxy plate with cutout

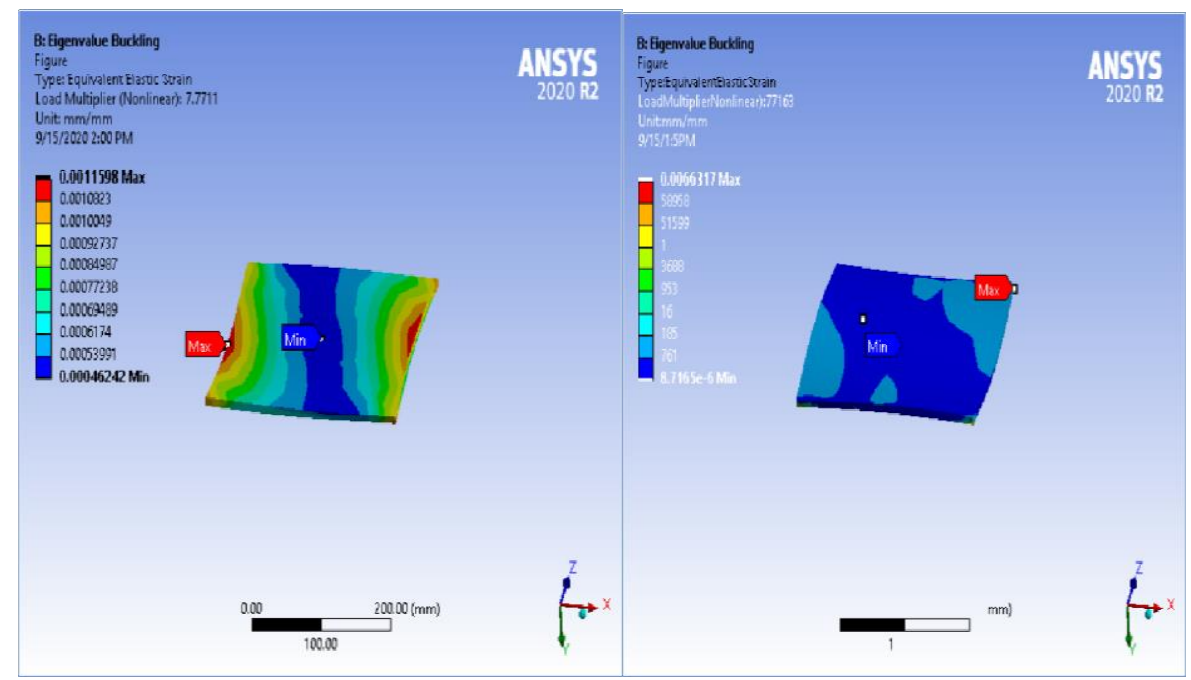

Figure 13. Equivalent elastic strain after buckling in carbon epoxy plate.

Figure13 shows the Equivalent elastic strain after buckling in carbon epoxy plate. 


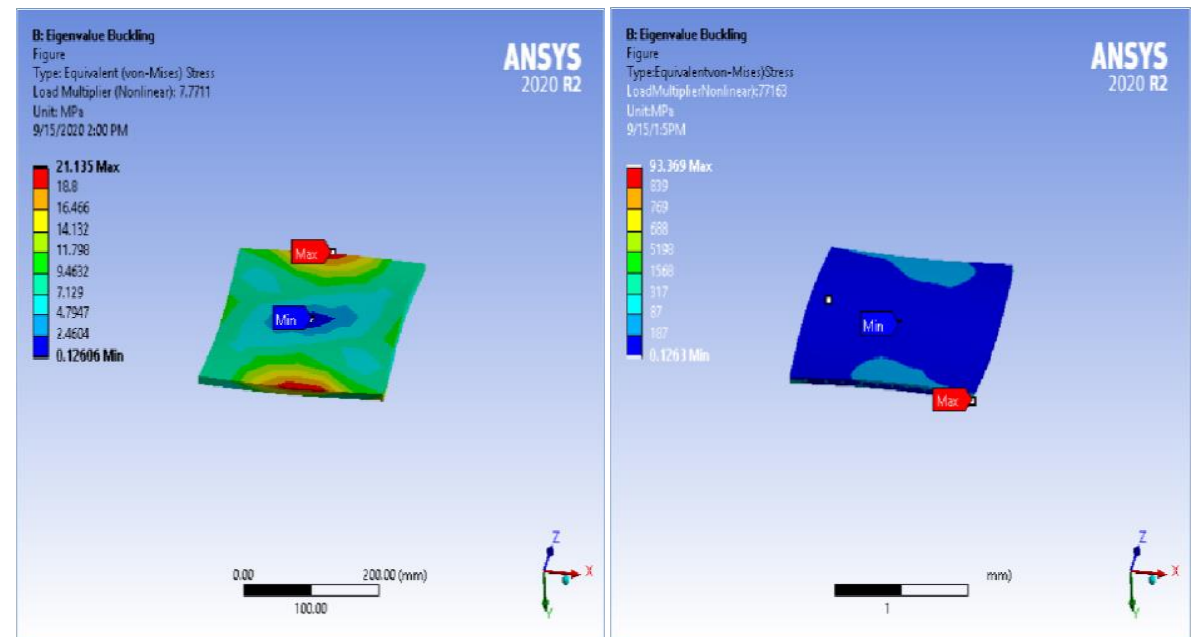

Figure 14. Equivalent elastic strain after buckling in carbon epoxy plate with cutout.

Figure 14 shows the Equivalent elastic strain after buckling in carbon epoxy plate with cutout.

\section{Applications of SMA}

The distinct features of SMAs have been used indifferent applications in civil engineering.

This section tries to analyze these applications in both newly constructed structures and retrofitted structures.

SMA in new structures

Considerable research has been performed on using SMA in building new structures as reinforcement, bolted connections, restrainers, bracings, and prestressing strands.

Reinforcement in concrete structures

Bridges and buildings in seismic areas are vulnerable to critical deformation owing to excess lateral movements. Earthquake tolerant structures must be designed to act flexibly under medium earthquakes. Under high ground movements, it is not economically possible to construct structures, which will work elastically. In traditional seismic design, steel is anticipated to be yielding in order to expel energy when undergoing deformation permanently.

On the contrary, when SMA is utilized in the form of reinforcement, it will give up when coming under excessive seismic loads, but will not exhibit substantial deformations permanently.

Bolted joints

Beam-column and column-foundation joints are generally the weakest link in a structure when earthquake occurs. Super elastic-SMA materials can be efficiently used in these joints to decrease their susceptibility by consuming high amount of energy via massive plastic deformation and thereafter retaining from it.

Bracings

Salichs et al. (2001) performed a numerical study using a one-story prototype-building model made strong with super elastic-SMA (Ni-Ti) diagonal bracing wires which comes under a harmonic base excitation. The results reveal that extra damping rendered by super elastic SMA hysteresis decreased the peak displacement and avoided deformation in comparison with that of steel bracing with identical stiffness. Owing to a less degree of deformation, this should also change the repairing of frames much convenient even if a big earthquake occurs.

Prestressing

Prestressing concrete and masonry structures with SMA strands/wires has been observed to be a feasible choice. Both pretensioning and post-tensioning can be performed with the help of SMA. The advantages of using SMAs in prestressing consists of a) active control on the amount of prestressing with improved extra load carrying strength, b) no usage of jacking or strand-cutting, and c) none of elastic-shortening, friction and anchorage-losses with the passage of time.

\section{Discussion}

In the scenarios of Carbon Epoxy with no shape memory alloy there is an increase of $47.49 \%$ in total deformation as compared to carbon Epoxy with shape memory alloy. In the scenarios of Carbon Epoxy with no shape memory alloy there is a decrease of $131.95 \%$ in Equivalent Elastic Strains compared to carbon Epoxy with shape memory alloy. In the scenarios of Carbon Epoxy with no shape memory alloy there is a decrease of $160.26 \%$ in Equivalent Stresses compared to carbon Epoxy with shape memory alloy. In the scenarios of Carbon Epoxy with shape memory alloy Circular Cut-out there is a decrease of $89.55 \%$ in total deformation as compared to carbon Epoxy with no shape memory alloy. In the case of Carbon Epoxy with shape memory alloy Circular Cut-out there is a decrease of $67.40 \%$ in Equivalent Elastic Strain as compared to carbon Epoxy without shape 
memory alloy. In case of Carbon Epoxy with shape memory alloy Circular Cut-out there is increase of $137.65 \%$ in Equivalent Stress as compared to carbon Epoxy without shape memory alloy In case of Carbon Epoxy without shape memory alloy Circular Cut-out there is decrease of $31.52 \%$ in total deformation as compared to Carbon Epoxy with shape memory alloy Circular Cut-out In case of Carbon Epoxy without shape memory alloy Circular Cut-out there is increase of $384.92 \%$ in Equivalent Elastic Strain as compared to Carbon Epoxy with shape memory alloy Circular Cut-out In case of Carbon Epoxy without shape memory alloy Circular Cut-out there is decrease of $81.06 \%$ in Equivalent Stresses compared to Carbon Epoxy with shape memory alloy Circular Cut-out In case of Carbon Epoxy with shape memory alloy there is decrease of 81.06\% in total deformations compared to Carbon Epoxy without shape memory alloy Circular Cut-out In case of Carbon Epoxy with shape memory alloy there is decrease of $81.06 \%$ in Equivalent Elastic Strain as compared to Carbon Epoxy without shape memory alloy Circular Cut-out In case of Carbon Epoxy with shape memory alloy there is increase of $784.38 \%$ in Equivalent Stresses compared to Carbon Epoxy without shape memory alloy Circular Cut-out.

\section{References}

1. L. C. Brinson1993 "FINITE ELEMENT ANALYSIS OF THE BEHAVIOR OF shape memory alloyS AND THEIR APPLICATIONS,” vol. 30, no. 23, pp. 3261-3280.

2. S. A. Chavan, S. S. Gawade, and S. B. Kumbhal, 2013 "Dynamic Behaviour of Composite Beam Embedded with Shape Memory Alloy Wires," pp. 692-695.

3. R. Damansabz and F. Taheri-behrooz, 2019 "Actuation of a carbon/epoxy beam using shape memory alloy wires,”, DOI: 10.1177/1045389X18810807.

4. A.Jafari and H. Ã. Ghiasvand,2008 “ARTICLE IN PRESS Dynamic response of a pseudoelastic shape memory alloy beam to a moving load," vol. 316, pp. 69-86, , DOI: 10.1016/j.jsv.2008.02.042.

5. S. M. R. Khalili, M. B. Dehkordi, and M. Shariyat, 2013 "Applied Mathematics and Computation Modeling and transient dynamic analysis of pseudoelastic shape memory alloy hybrid composite beam," Appl. Math. Comput., DOI: 10.1016/j.amc.2013.03.092.

6. N. Van Viet and W. Zaki, 2019 "Bending theory for laminated composite cantilever beams with multiple embedded shape memory alloy layers,", DOI: 10.1177/1045389X19835954.

7. V. Birman and I. Rusnak, 2011 "Vibrations of plates with superelastic shape memory alloy wires,", DOI: 10.1007/s10665-011-9483-3.

8. S. M. R. Khalili and A. Saeedi, 2017 "Dynamic response of laminated composite beam reinforced with shape memory alloy wires subjected to the low-velocity impact of multiple masses,", DOI: 10.1177/0021998317722042.

9. S.M.R. Khalili, M. BotshekananDehkordi, M. Shariyat,2013 Modeling and transient dynamic analysis of pseudoelasticshape memory alloy hybrid composite beam, Applied Mathematics and Computer 219762-9782.

10. Niknami, M. Shariyat, 2016Refined constitutive, bridging, and contact laws for including effects of the impact-induced temperature rise in impact responses of composite plates with embedded shape memory alloy wires, Thin-Walled Structure106 166-178.

11. SinaHassanli, Bijan Samali.2016 "Buckling analysisof laminated composite curved panelsreinforced with alinear and non-linear distributionof Shape Memory Alloys", Thin-Walled Structures,

12. Shariyat, M., M. Moradi, and S. Shape Memory Alloy.2013"Enhanced model for nonlinear dynamicanalysisof rectangular composite plates with embedded shape memory alloy wires, considering the instantaneous local phase changes", Composite Structures.

13. ShokuhfarS.M.R. KhaliliF. AshenaiGhasemiK. MalekzadehS. Raissi2008"Analysis and optimization ofsmart hybrid composite plates subjected to low-velocity impact using the response surface methodology (RSM)" thin-walled structure 46, issue 11, November, pages 1204-1214.

14. M.M.Ghomsheia,N. Tabandeh, Ghazavi F. Gordanineja.2005 "Nonlinear transient response of a thick composite beam with shape memory alloy layers"Composites Part B: EngineeringVolume 36, Issue 1, January, Pages 9-24

15. Dinesh Kumar S.B. Singh 2012"Stability and failure of composite laminates with various shaped cutouts under combined in-plane loads" Composites Part B: EngineeringVolume 43, Issue 2, March, Pages 142-149.

16. JaronieMohdJani, Martin Leary, Aleksandar Subic, Mark A. Gibson, "A review of shape memory alloy research, applications and opportunities" elsevier, 2013.

17. Salichs, J., Hou, Z., and Noori, M. 2001. Vibration suppression of structures using passive shapememory-alloy energy dissipation devices. Journal of Intelligent Material Systems and Structures, 12: $671-680$. 


\section{Biographies}

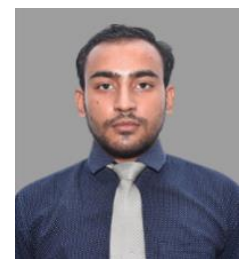

Yatendra Saraswat, Assistant Professor, GLA University, Mathura, U.P(India). M.Tech in Structure from GLA University, Mathura. Email: yatendrasaraswat52@gmail.com

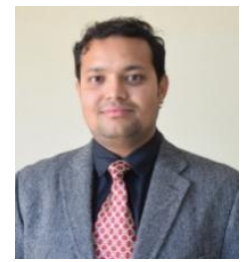

Hemant Singh Parihar Assistant Professor GLA University, Mathura U.P.(India). M.Tech in Structural Engineering from MNNIT Allahabad. 